\title{
Cadernos Espinosanos
}

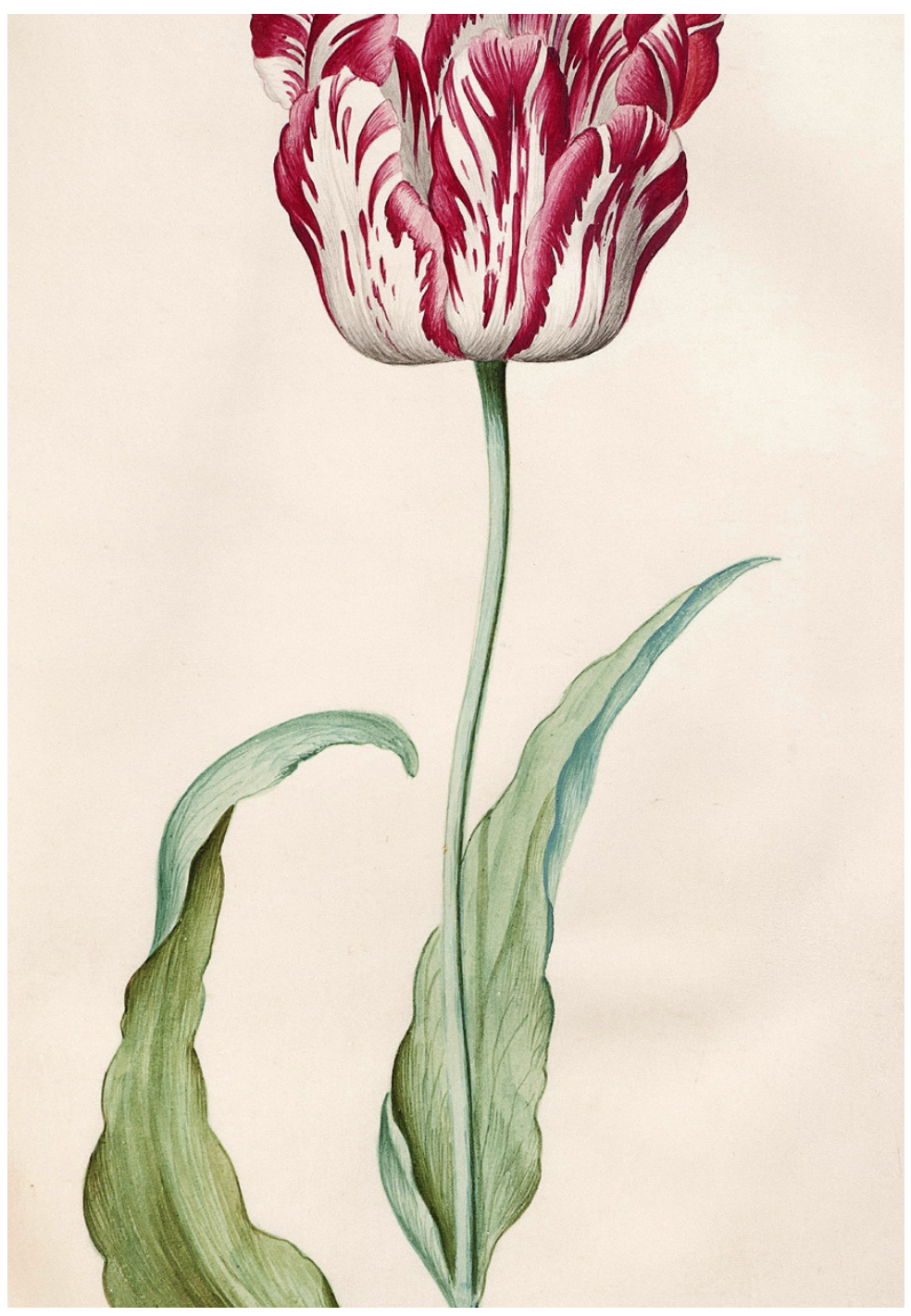

ESTUDOS SOBRE O SÉCULO XVII
n. 45 jul-dez 2021 ISSN 1413-6651 
IMAGEM Detalhe de pintura de Judith Leyster (1609-1660) extraído Do Livro de Tulipas (1643). Leyster foi a pintora mais famosa da Idade de Ouro holandesa, tendo alcançado um grau de sucesso artístico raro para uma mulher em sua época. Em 1633, tornou-se a primeira mulher a ser admitida como pintora mestre na prestigiosa Guilda de Pintores de Haarlem, obtendo assim o direito de estabelecer seu próprio ateliê-loja e de assumir alunos. 


\title{
A QUESTÃO DO INFINITO EM PASCAL E ESPINOSA
}

\author{
Rodrigo Hayasi Pinto \\ Professor, Pontifícia Universidade Católica do Paraná, \\ Curitiba, Brasil \\ rhayasi48@gmail.com
}

RESUMO: O presente artigo tem como objetivo principal demonstrar que o pensamento do filósofo francês Blaise Pascal nunca esteve alheio às principais discussões metafísicas do século XVII. A discussão que será explorada aqui está relacionada com a questão do infinito, abordada com ênfase pelos autores desse período. Com esse objetivo em mente, tentar-se-á construir uma argumentação sobre a questão do infinito no âmbito da metafísica a partir de dois filósofos do século Xvir: Blaise Pascal e Baruch Espinosa. Tentaremos mostrar que a reflexão filosófica de Pascal, por um lado, se assemelha à de Espinosa quando assume que Deus deve ser concebido como absolutamente infinito, acima de qualquer gênero específico de infinitude, seja matemático ou espacial, mas se afasta do filósofo holandês, quando Pascal assume a impossibilidade de o homem compreender o infinito em termos absolutos por intermédio da racionalidade.

PalaVras-chave: Infinito, Geometria, Matemática, Deus, Metafísica, Limite 
INTRODUÇÃO

Grande parte dos pensadores do século XVII construiu uma concepção epistemológica baseada em modelo matemático. Descartes, Galileu e Leibniz, por mais divergentes que sejam suas teorias, têm em comum o fato de que construíram a concepção de um método de conhecimento dentro do âmbito da evidência, da análise e da interpretação da natureza a partir da matemática. É possível também afirmar, nesse sentido, que os pensadores do século XVII partiram do modelo matemático para construir suas teorias metafísicas. O encadeamento lógico das razões concebido por Descartes nas Meditaçoes Metafísicas, a Monadologia de Leibniz construída a partir da ideia do ponto central (mônada) de onde concorrem "todos os raios da ação universal" (BRUNSCHVICG, 1945, p. 253), a Ética baseada em modelo geométrico de Espinosa, todas essas obras têm como referência primordial o pensamento matemático.

No entanto, há um pensador capital do século XVII que, embora seja considerado grande matemático e geômetra, comumente não é colocado ao lado dos grandes metafísicos desse período: trata-se de Blaise Pascal. Talvez isso se deva ao caráter assistemático de sua filosofia, a qual não tem como objetivo principal construir uma visão metafísica da realidade, onde a categoria de substancialidade e de ser adquira primazia, e consequentemente não visa explicar o real a partir de um sistema fechado e acabado. A filosofia de Pascal é uma crítica justamente aos pensadores sistemáticos da filosofia, que partem do pressuposto de que o âmbito da racionalidade, vinculado à esfera do pensamento geométrico e lógico-dedutivo, é passível de chegar à compreensão do todo, abarcando a realidade em todos os seus pormenores.

Além disso, algo digno de nota é que, embora Pascal tenha publicado alguns opúsculos dedicados ao pensamento matemático 
e geométrico, sua principal obra, os Pensamentos, não é caracterizada como obra de inspiração matemática ou geométrica, mesmo que alguns fragmentos façam uma análise da realidade física e antropológica a partir de princípios matemáticos e geométricos. Tal fato se torna compreensível quando sabemos que o projeto original dessa obra culminaria, se houvesse sido escrita como planejado, numa futura Apologia da Religião Cristã. Nesse sentido, poderíamos ser levados a pensar que a adesão de Pascal ao pensamento religioso e cristão poderia ter afastado a reflexão do pensador francês das questões matemáticas e geométricas e o teria levado na direção da reflexão teológica. Mas isso efetivamente não ocorreu.

Nossa intenção no presente artigo, portanto, é defender a posição de que Pascal, quando se converteu ao Jansenismo, não abandonou completamente a reflexão gerenciada pela lógica, pela geometria e pela matemática. Nesse sentido, sua "armadura conceitual” anterior, desenvolvida ao longo dos anos de formação como matemático, físico e geômetra, não teria sido "quebrada" pelo espírito religioso. O que ocorreu é que o espírito religioso complementou seu pensamento lógico, fornecendo uma visão cosmológica e antropológica mais ampla, tornando-se propriamente um grande instrumento interpretativo. Como Lebrun aponta:

[...] O cristianismo deve ser analisado como um instrumento nas mãos de Pascal. Pascal só teria sido quebrado pelo cristianismo se tivesse se contentado a se submeter cegamente a seus dogmas e a suas normas de vida - se se tivesse 'bestializado' por fanatismo ou masoquismo (LEBRUN, 1983, p. 123).

Nesse caso, não houve submissão cega e dogmática à concepção cristã, a ponto de obscurecer seu espírito científico. Alguns filósofos, como Michel Serres, por exemplo, apontam que uma das questões presentes nos Pensamentos, anterior a qualquer pressuposto teológico, é a busca pelo ponto 
fixo, e que o fato de Pascal ter encontrado um referencial antropológico na religião cristã é um indicativo de que as mesmas exigências encontradas em alguns tratados de geometria, assim como no que ele chama de Razão dos Efeitos, estão também presentes na reflexão cosmológica e antropológica dos Pensamentos.

Segundo Serres, na antropologia pascaliana constatamos, em primeiro lugar, que "[...] a busca do ponto fixo está inscrita em nossa alma e em nosso desejo" (SERRES, 1968, p.678) e, em segundo lugar, constatamos que somente Deus pode desempenhar esse papel: "quem pode assinalar novamente o polo de meu universo e o centro de minha alma, senão aquele que conhece os limites da circunferência, aquele em quem 'as extremidades se tocam e se reúnem à força de serem afastadas', aquele em que elas se reencontram: Deus e Deus somente". (SERres, 1968, p.682). Nesse sentido, há certas razões epistemológicas, e porque não dizer lógicas, além daquelas de natureza existencial e antropológica, que teriam levado o pensador jansenista a assumir um referencial de natureza religiosa, ou seja, a adotar o Deus cristão como ponto fixo.

Por outro lado, Léon Brunschvicg, comentador e organizador da célebre edição Brunschvicg dos Pensamentos de Pascal, publicada em 1897, afirma que, em Pascal, há uma espécie de integração entre o sentimento do cristão dado pela graça e a ciência que permite restabelecer os princípios desta numa ordem superior de realidade. Brunschvicg afirma, de modo enfático, que na filosofia pascaliana há uma "aliança" entre o pensamento "positivista" e científico do autor e o misticismo cristão. Portanto, nesse caso, não há negação do pensamento científico pela perspectiva cristã:

Só uma experiência específica, comparável à obra experimental do físico, ou ainda ao sentimento do cristão sob a ação da graça, per- 
mite restabelecer os verdadeiros princípios da ciência em esfera superior ao domínio da razão. Isso explica, na filosofia de Pascal, a aliança de um certo positivismo com um certo misticismo, que seduziu a mais de um de nossos contemporâneos (BRUNSCHVICG, 1945, p. 198).

Uma das questões que queremos abordar, presente nos Pensamentos, que apontam para a autonomia do pensamento racional diante de qualquer pressuposto teológico, ao mesmo tempo que alude a uma reflexão ao nível da filosofia da matemática e da metafísica, é a discussão em torno da ideia do infinito, presente no fragmento Br.72/ Laf.199 e no célebre fragmento da aposta, Br.233/Laf.418. Segundo pensamos, a discussão apresentada por Pascal nesses fragmentos lança luz sobre a questão do infinito abordada por alguns pensadores do século XVII, como Descartes e Espinosa. Nesse sentido, o que pretendemos mostrar é que a filosofia de Pascal, presente nos Pensamentos, é capaz de se avizinhar e até mesmo ombrear ao nível da discussão com certas questões metafísicas de outros pensadores do século xVII.

A QUESTÃO DO INFINITO EM PASCAL

Segundo Deleuze, citando Merleau-Ponty, uma das questões capitais daquilo que o filósofo vai chamar de "O Grande Racionalismo" do século XVII, é a reflexão voltada para a ideia de "infinito positivo", que encontra sua consumação máxima na filosofia de Baruch Espinosa:

Merleau-Ponty frisou bem aquilo que hoje nos parece ser o mais difícil de compreender nas filosofias do século XVII: a ideia do infinito positivo como 'segredo do grande racionalismo', 'uma maneira inocente de pensar a partir do infinito', cuja perfeição se encontra no espinosismo (DELEUZE, 2017, p. 30). 
Ora, a nosso ver, Pascal não deve ser considerado um pensador alheio a essas grandes questões vinculadas ao grande racionalismo, particularmente a reflexão vinculada à ideia de infinito. No fragmento $\mathrm{Br}$.72/ Laf.199, por exemplo, intitulado Desproporção do Homem, Pascal oferece um retrato do homem como um ser insignificante e extraviado no interior de um universo infinito.

Que o homem, voltado para si próprio, considere o que é diante do que existe; que se encare como um ser extraviado neste canto afastado da natureza, e que, da pequena cela onde se acha preso, isto é, do universo, aprenda a avaliar em seu valor exato a terra, os reinos, as cidades e ele próprio. Que é um homem dentro do infinito? (PASCAL, 1973, pensamento Br.72/Laf.199, p. 51).

A partir da ideia da configuração do homem no interior do universo infinito, Pascal nos oferece a imagem de uma dupla infinitude. Primeiramente nos deparamos com um infinito de grandeza decorrente do fato de que há infinitas coisas que nos ultrapassam em dimensão, proporção e tamanho. Nesse caso, a própria morada do homem, a Terra, se apresenta como um ponto insignificante em relação ao Sol e os outros planetas. Em outras palavras, por maior que seja o nosso planeta e aquilo que conseguimos vislumbrar com a nossa visão e a superioridade de nossos conhecimentos, tudo aquilo que percebemos e vemos não passa de uma perspectiva limitada e, portanto, finita, quando concebemos que existe a possibilidade da existência de infinitos mundos dentro de um universo infinito e que uma distância infinita nos separa desses mundos.

Considere essa brilhante luz colocada acima dele [do homem] como uma lâmpada eterna para iluminar o universo e que a terra lhe apareça como um ponto na órbita ampla desse astro, e que se maravilhe de ver que essa amplitude tampouco passa de um ponto insignificante na rota dos outros astros, que se espalham 
pelo firmamento [...]. Todo esse mundo visível é apenas um traço imperceptível na amplidão da natureza, que nem sequer nos é dado conhecer mesmo de um modo vago. Por mais que ampliemos as nossas concepções e as projetemos além dos espaços imagináveis, concebemos tão somente átomos em comparação com a realidade das coisas. (PASCAL, 1973, pensamento Br.72/Laf.199, p. 51).

Por outro lado, Pascal descreve outra ordem de infinitude, relacionada às menores coisas que ao homem é dado conhecer. Se dividíssemos as menores coisas, nos depararíamos com elementos ainda menores, passíveis de divisão, havendo a possibilidade de uma divisão ininterrupta. Nesse caso, mesmo se atingíssemos as dimensões atômicas, o próprio átomo seria divisível. Pascal se utiliza da imagem de uma lêndea sendo anatomizada pelo homem. Poderíamos cortá-la em partes menores e mesmo assim haveria sempre a possibilidade de prosseguir nessa divisão perpetuamente. Essa ordem de infinitude pode ser chamada de infinito de pequenez, por envolver a divisibilidade infinita das menores coisas.

Quero, porém, apresentar-lhe outro prodígio igualmente assombroso, colhido nas coisas mais delicadas que conhece. Eis uma lêndea que, na pequenez de seu corpo, contém partes incomparavelmente menores, pernas com articulações, veias nessas pernas, sangue nessas veias, humores nesse sangue, gotas nesses humores, vapores nessas gotas; dividindo-se estas últimas coisas, esgotar-se-ão as capacidades de concepção do homem, e estaremos, portanto, ante o último objeto a que possa chegar o nosso discurso. Talvez ele imagine, então, ser essa a menor coisa da natureza. Quero mostrar-lhe, porém, dentro dela um novo abismo. [...] Aí existe uma infinidade de universos, cada qual com o seu firmamento, seus planetas, sua terra em iguais proporções às do mundo visível [...] (PASCAL, 1973, pensamento Br.72/Laf.199, p. 51).

Desse modo, diante dessas duas ordens de infinitude, o homem não tem nenhum critério situacional para avaliar que lugar ele ocuparia no interior dessa dupla escala de infinitude. Com efeito, para Pascal, o homem 
é algo e não tudo. Mas, em que consistiria esse "algo", na medida em que o homem ocupa uma posição intermediária entre o universo infinito que o envolve como um todo, que ele não pode abarcar, e o infinito de pequenez, que não lhe permite perceber qual é a essência última, que constitui a própria realidade material, à qual pertence enquanto possui um corpo físico? A resposta é que não há critério de compreensão que nos leve a conhecer a natureza desse "algo", pois não há demarcação possível do que seria esse "algo". Nesse sentido, Pascal conclui:

Afinal, que é o homem dentro da natureza? Nada em relação ao infinito; tudo em relação ao nada; um ponto intermediário entre tudo e nada. Infinitamente incapaz de compreender os extremos, tanto o fim das coisas como o seu princípio permanecem ocultos num segredo impenetrável, e é-lhe igualmente impossível ver o nada de onde saiu e o infinito que o envolve (PASCAL, 1973, pensamento Br.72/Laf.199, p. 52).

A situação mediana do homem, portanto, não confere alcance ontológico suficiente para que este possa perceber o que é em termos essenciais. Por outro lado, Pascal se diferencia de modo mais profundo dos pensadores desse período. Se muitos pensadores modernos se caracterizam por apontarem para a inutilidade da determinação da causa final, que nada nos diria como princípio explicativo do fenômeno natural, detendo-se na pressuposição da causa eficiente, tanto para explicar os fenômenos físicos, quanto para explicar a ordem mecânica do universo como um todo, Pascal, de modo mais enfático, aponta para a impossibilidade de se apontar a própria causa eficiente de modo absoluto, como princípio de uma ordem natural, seja ela mecânica, orgânica ou metafísica. Não há como determinar os princípios metafísicos que sustentam a natureza, já que, conforme dito linhas acima, "tanto o fim das coisas, como o seu princípio permanecem ocultos num segredo impenetrável" (grifo nosso) (PASCAL, 1973, pensamento Br.72/Laf.199, p. 52). 
Esse "segredo impenetrável", sintoma dessa limitação ontológica, desempenha papel de destaque quando se trata de realizar uma discussão comparando Pascal com outros autores do século xviı que trataram da questão do infinito, relacionando-o à natureza de Deus. Mesmo que aqui Pascal não se refira a Deus diretamente, ele abre espaço, a partir da discussão operada no pensamento Br.72/Laf.199, para que problematizemos a possibilidade de apontar racionalmente um Deus criador como causa eficiente do mundo. Em outras palavras, até que ponto é possível determinar racionalmente, da perspectiva humana, que Deus, ser infinito, é causa da existência do mundo e do próprio universo infinito, quando existe uma impossibilidade nesse sentido, relacionada ao fato de que não podemos ultrapassar o abismo de infinitude que nos envolve, que nos permitiria perceber, de modo racional, que Deus é a causa eficiente e o supremo criador do universo?

No entanto, não é no fragmento Br.72/Laf.199 que Pascal tece considerações teológicas acerca de Deus e o infinito. Com efeito, a dupla infinitude, debatida aqui, é aquela presente na relação entre o homem e a natureza e não corresponde ao infinito relacionado à natureza divina. Embora, é claro, a impossibilidade de conhecer a totalidade infinita que nos envolve, bem como chegar a compreender os princípios últimos que fundamentam a realidade, nos leve a um reconhecimento de nossa ignorância e de nossa limitação em relação a tudo aquilo que ultrapassa a nossa razão; consequentemente, é possível concluir, por essa via, que não podemos assumir Deus, devido aos limites que demarcam nossa perspectiva humana e finita, como causa eficiente do universo. É no fragmento Br. 233/Laf.418 que Pascal vai propor um questionamento mais aprofundado acerca da impossibilidade de conhecermos Deus racionalmente, afirmando algo acerca da condição infinita deste ser. 
Conhecemos a existência e a natureza do finito porque somos finitos e extensos como ele. Conhecemos a existência do infinito e ignoramos a sua natureza, porque tem extensão, como nós, mas não limite como nós. Não conhecemos nem a existência nem a natureza de Deus, porque não tem extensão nem limites (PASCAL, 1973, pensamento Br.233/Laf.418, p. 94).

Segundo o filósofo francês, a ciência das coisas finitas não apresenta problemas, visto que, por sermos seres finitos e limitados, o conhecimento dessa ordem de realidade resulta logicamente possível, concordando com nossa perspectiva finita e o alcance limitado de nosso conhecimento. Ora, o mesmo não se dá em relação ao infinito; nesse caso não podemos conhecêlo, mas podemos apenas apontar para a possibilidade de sua existência. Com efeito, podemos pressupor a existência do infinito em termos extensos e espaciais, por exemplo, porque há um princípio analógico, a ideia de extensão ilimitada, que nos permite apontar para a existência de uma extensão infinita.

Podemos, por outro lado, trabalhar com o conceito de infinito operativamente, através da matemática, para conhecer a incomensurabilidade da natureza que nos envolve, por exemplo, conforme foi mostrado acima, multiplicando as coisas e daí pressupondo que há infinitas coisas que nos ultrapassam ou dividindo as menores coisas infinitamente e pressupondo que não há um término na divisão. No entanto, não podemos conhecer a sua natureza, tratando-o como um objeto do conhecimento, pois, como somos seres finitos, não temos uma medida comparativa que permita mensurar e compreender o infinito na sua totalidade. Desse modo, diz Pascal:

Sabemos que há um infinito e ignoramos a sua natureza. Como 
sabemos que é falso que os números sejam finitos, logo é verdade que há um infinito em número. Mas, não sabemos o que ele é: é falso que seja par, é falso que seja ímpar, pois acrescentando-lhe a unidade ele não muda de natureza; entretanto é um número, e todo número é par ou ímpar (PASCAL, 1973, pensamento Br.233/ Laf.418, p. 94).

Ora, é justamente essa noção de que há um abismo infinito que nos aparta da natureza das coisas e do conhecimento do absoluto que nos impede de fazer afirmações relacionadas à natureza de Deus, como, por exemplo, a de que ele pode e deve ser considerado causa da existência do mundo. Mas, ao menos podemos afirmar que ele existe? Segundo Pascal, além de não podermos afirmar algo acerca da natureza de Deus, visto sua natureza ser infinita, em contrapartida também não podemos provar e demonstrar a sua existência, visto que a natureza infinita de Deus não é da ordem da infinitude espacial e geométrica, a qual está relacionada ao conhecimento meramente racional.

Nesse caso, Deus corresponde ao infinito absoluto, que não estabelece nenhuma relação com o homem, ser finito que mantém relação apenas com as coisas finitas, não obstante ele possa pressupor a existência do infinito na geometria e na matemática. Assim, não podemos conhecer a existência e a natureza de Deus, porque tal ser não tem extensão nem limites. Em outras palavras, Deus transborda para longe do alcance da razão, articulada pelos princípios lógico-geométricos, notadamente a ideia de extensão. Deus está fora dos limites da razão, na medida em que não podemos fazer qualquer afirmação ou demonstração lógico-racional, que nos possibilitaria que nos inclinássemos mais para sua existência do que para sua não existência ${ }^{1}$. Desse modo, Pascal conclui o argumento:

I No caso do infinito numérico ou espacial, por exemplo, é possível apostar na sua 
Se há um Deus, ele é infinitamente incompreensível, pois, não tendo partes nem limites, não tem nenhuma relação conosco. Somos, portanto, incapazes de conhecer não só o que ele é como também se existe. Assim sendo, quem ousará resolver a questão? Não seremos nós que não temos qualquer relação com ele (PASCAL, 1973, pensamento Br. 233/Laf.418, p. 95, grifos nossos).

O homem, finito e relativo a todos os seres e coisas finitas que compõem o universo, não estabelece nenhuma relação com o absoluto. Nesse caso, Deus é definido, literalmente, como um ser absoluto, pois não sendo relativo àquilo que é finito, não estabelece nenhuma relação com o homem. Logo, Pascal conclui, Deus é infinitamente incompreensível pela perspectiva humana. Tomar Deus como um ser absoluto implica a impossibilidade da racionalidade conhecer a própria natureza do absoluto, inferindo a sua existência. Quando se trata do infinito matemático e geométrico, podemos conhecê-lo relacionando-o com a ideia de uma sucessão numérica ininterrupta e com a noção de uma extensão infinita e ilimitada. É, portanto, um infinito relativo à noção de sucessão numérica e de extensão, ou podemos dizer que há um princípio matemático e geométrico, a ideia de infinito nessas ciências, que permite fazer a analogia.

Ora, quando se trata do infinito absoluto não é possível fazer nenhuma analogia, em termos matemáticos e geométricos, pois este não

existência, a partir de uma prova pelo absurdo, em que se afirma a verdade de uma proposição, mostrando a falsidade da proposição contrária, como o próprio Pascal aponta: "sabemos que há um infinito, e ignoramos a sua natureza. Como sabemos que é falso que os números sejam finitos, logo é verdade que há um infinito em número." (PASCAL, 1973, pensamento Br.233). Porém, quando se trata da afirmação da existência de Deus não há essa possibilidade, pois a proposição contrária à de que ele não existe também não pode ser provada racionalmente como absurda. 
é da ordem da quantidade e nem da extensão espacial. Há, portanto, limites muito fortes quando se trata de conhecer o que seria o infinito em termos absolutos. Entretanto, podemos fazer outro tipo de analogia no âmbito desses limites: a partir da impossibilidade do homem conhecer Deus racionalmente, por ser um infinito sem extensão espacial e, portanto, não composto de partes, podemos fazer uma analogia com outra questão, presente tanto nos Pensamentos quanto no opúsculo "Do Espírito Geométrico". Trata-se da questão da impossibilidade de conhecermos o que seria algo indivisível.

No fragmento Br.72/Laf.199, Pascal aponta que, dividindo-se as menores coisas, jamais chegaríamos a um momento em que essa divisão se interrompesse, ou seja, jamais chegaríamos a partes indivisíveis, não passíveis de divisão. Ora, no opúsculo Pascal faz uma reflexão semelhante à do fragmento Br.72/Laf.199, a partir dos primeiros princípios que sustentam o método geométrico. Pascal aponta que quando se trata do número, do movimento, do espaço e do tempo, não podemos jamais atingir o zero absoluto, o repouso absoluto, o indivisível e o nada de duração. Assim, o indivisível, relacionado à extensão espacial, não pode ser apreendido quando a racionalidade opera com sucessivas divisões. Há limites no discurso lógico-dedutivo que impedem essa apreensão. "Isto é, numa palavra, seja qual for o movimento, o número, o espaço, o tempo, há sempre um maior e um menor, de modo que todos eles se sustêm entre o nada e o infinito, estando sempre infinitamente afastados desses extremos" (PASCAL, 1963, p. 352a).

No entanto, a partir daí não é lícito concluir pela impossibilidade da existência do indivisível, visto que ele pertence a uma outra ordem de realidade. Ele é de outro gênero. Embora não possamos conceber o indivisível racionalmente, por intermédio de sucessivas divisões, podemos 
conceber a possibilidade de sua existência. Como o próprio Pascal afirma: "Incompreensível? - Nem tudo que é incompreensível deixa de existir" (PASCAL, 1973, pensamento Br.430/Laf.149, p. 141).

Um indivisível é aquilo que não tem parte alguma e a extensão é o que tem diversas partes separadas. [...] Pela mesma razão, se mostrará a mesma coisa de todos os outros indivisíveis que a eles se juntar. E, portanto, um indivisível, multiplicado tanto quanto se quiser, não formará jamais uma extensão. Logo, ele não é do mesmo gênero da extensão, pela definição das coisas do mesmo gênero (PASCAL, 1963, p. 354a).

Nesse caso, podemos dizer que Deus, embora não seja uma entidade geométrica, estaria situado, em termos de distância infinita em relação ao homem, de modo mais distante ainda do que esse ponto imperceptível e indivisível em relação à extensão. No entanto, é possível fazer uma analogia: mesmo não pertencendo ao âmbito da geometria, a essência infinita de Deus não pode ser apreendida racionalmente em termos matemáticos e espaciais, assim como o ponto indivisível não pode ser incluído na ideia de extensão espacial. Em outras palavras, o infinito vinculado a Deus não tem partes, mesmo que essas sejam ilimitadas, e desse modo não se dá a perceber ou conhecer pelo homem através da racionalidade, a qual somente pode conceber o infinito vinculado à extensão, ao número, ao movimento e ao tempo, e nesse sentido é semelhante à noção de um indivisível não composto de partes, embora, obviamente, não seja do mesmo gênero deste. $\mathrm{O}$ indivisível não permite estabelecer relação com nenhuma noção vinculada à extensão, pois não possui partes que o constituem, e assim, a ideia do indivisível seria analogicamente semelhante à ideia de um todo não constituído por partes, a qual se aproxima da concepção de Deus como infinito em sentido absoluto. 
Desse modo, é possível dizer que quando Pascal discute, no fragmento Br.233, a questão de Deus como “infinitamente incompreensível”, ele estaria também, tal como outros autores do XVII, falando acerca do absolutamente infinito como algo não pertencente a qualquer gênero. Nesse caso, estaria ele personificando uma discussão muito presente no século XVII sobre a natureza infinita de Deus. Conforme apontamos no início do artigo, para Merleau-Ponty, na tradição metafísica do século XVII adquiria importância primordial a discussão em torno do conceito de infinito positivo. Ora, a filosofia pascaliana não estaria alheia à discussão acerca da natureza infinita de Deus, como comprova o fragmento Br.233/ Laf.418; no entanto, quando Pascal fala sobre a infinitude divina, o que é digno de nota é que ele não desemboca na possibilidade de se pensar o absolutamente infinito em moldes conceituais.

De modo contrário, ele conclui pela ideia de uma infinitude divina que institui uma espécie de distância infinita entre Deus e o homem, já que não pertence ao gênero do infinito encontrado nas ciências matemáticas. Logo, quando se trata de relacionar o conceito de infinito a Deus, a principal consequência é uma espécie de negatividade no pensamento de Pascal, o que o leva a concluir pela incompreensibilidade quando se trata de Deus, e não pela afirmação de um infinito positivo passível de ser conhecido pelo homem ou compreendido pela razão. Em outras palavras, a questão da infinitude divina tangencia a questão dos limites do conhecimento, isto é, aquilo que pode ou não ser conhecido pelo homem segundo a filosofia pascaliana.

Uma das primeiras coisas que chama a atenção quando comparamos a concepção de Pascal no que tange a Deus no fragmento Br. 233/Laf.418 com a concepção dos outros autores do XVII que também 
abordam essa questão é que a concepção pascaliana de infinito não implica a prova da existência de Deus. Nas Meditações, por exemplo, Descartes prova a existência de Deus por intermédio da ideia de infinito presente na mente do homem. Com efeito, segundo Descartes, eu não posso ser causa dessa ideia pois sou um ser finito e, nesse sentido, apenas posso conceber e representar ideias finitas. Ora, há uma ideia que corresponde a uma substância infinita em minha mente, logo, eu, substância finita, não posso ser a causa dessa ideia. Portanto, a causa dessa ideia só pode ser uma substância infinita, no caso Deus.

E, por conseguinte, é preciso necessariamente concluir de tudo o que disse anteriormente que Deus existe; pois, ainda que a ideia da substância esteja em mim, pelo próprio fato de eu ser uma substância, eu não teria, contudo, a ideia de uma substância infinita, eu que sou um ser finito, se ela não tivesse sido posta em mim por alguma substância que fosse verdadeiramente infinita (DESCARTES, 2016, p. 72).

A ideia de infinito em Descartes encontra-se vinculada à noção de perfeição. O homem, sendo imperfeito, e uma marca disso é a própria necessidade de usar o artifício da dúvida para encontrar a verdade, tem em sua mente uma ideia clara e distinta, vinculada à perfeição divina, aquela correspondente ao infinito, a qual deve ser considerada a marca do criador na criatura. Em outras palavras, segundo Descartes, o infinito presente na mente do homem não corresponde à negação da ideia de finito, mas é uma ideia positiva, relacionada à natureza perfeita de Deus. Pascal, de modo contrário, não considera o infinito como uma representação ou uma ideia clara e distinta, presente na mente do homem, e que revelaria a natureza de Deus, mas o infinito é justamente a noção que aparta o homem da compreensão da natureza do próprio infinito e mais, que o anula diante de Deus. $\mathrm{Na}$ presença do infinito, o finito "se aniquila" tornando-se "um puro nada": 
A unidade acrescentada ao infinito em nada o aumenta, como não aumenta uma medida infinita um pé que a ela se acrescente. O finito se aniquila na presença do infinito e torna-se um puro nada. Assim, nosso espírito em face de Deus; assim nossa justiça em face da justiça divina (PASCAL, 1973, pensamento Br.233/Laf. 418, p. 94, grifos nossos).

Para Pascal, longe de o infinito ser uma ideia, um objeto do conhecimento que aproximaria o homem finito do ser infinito, que é Deus, levando-o à compreensão da essência divina, que tem como atributo a perfeição, ele é justamente a instância que aparta o homem de qualquer possibilidade deste ter uma ideia da natureza de Deus. Quando Pascal, no fragmento Br.72/Laf.199, fala em dividir tudo aquilo que é extenso, sem nunca interromper essa divisão, o que nos impossibilita a apreensão dos princípios últimos que fundamentam a natureza, ele apenas opera com a noção de infinitude, sem chegar a uma compreensão de qual seria a natureza desse infinito. Logo, mesmo quando Pascal se utiliza do infinito matemático e geométrico, esse gênero de infinitude não pode ser considerado uma ideia clara e distinta, pois não pode se constituir num objeto do conhecimento, já que não temos uma ideia clara do que seria sua natureza. Segundo Ivonil Parraz, em artigo publicado sobre a questão do infinito em Pascal:

A geometria concebida por Pascal permite a ele trabalhar com o conceito de infinito apenas como operação e não como objeto. Isto quer dizer que, para Pascal, como veremos a seguir, a razão pode operar com o conceito de infinito, sem fazer dele objeto de conhecimento, posto que o infinito escapa a todas as relações proporcionais que são propriamente o modo dela operar (PARRAZ, 2012, p. 267).

Desse modo, o infinito em Pascal, não sendo um objeto do conhecimento, que o elevaria à categoria de uma ideia clara e distinta, não pode levar o homem a construir um conhecimento certo e seguro sobre 
a sua natureza. Ora, tal constatação implica dizer que, quando se trata de Deus, a impossibilidade de conhecer sua natureza é muito maior. Em outras palavras, a incompreensão do que seria esse ser em sentido ontológico é maior do que aquela relacionada ao infinito extenso ou matemático, pois além de não podermos conhecer sua natureza e fazer afirmações sobre ela, também não podemos fazer afirmações sobre a sua possível existência.

Deus deve ser considerado, nesse fragmento, como um ser infinito fora de todo gênero espacial e geométrico, ou seja, está além dessas duas ordens de infinitude. Assim, longe da ideia de infinito levar a uma compreensão da essência de Deus, como ocorre em Descartes, podemos afirmar que, nesse caso, não é possível fazer uma analogia do infinito com a ideia de Deus, pois não há um correspondente em nossa mente que permita operar uma relação com a infinitude absoluta de Deus. Desse modo, Pascal conclui:

Se há um Deus, ele é infinitamente incompreensível, pois, não tendo partes nem limites, não tem nenhuma relação conosco. Somos, portanto, incapazes de conhecer não só o que ele é como também se existe. Assim sendo, quem ousará resolver a questão? Não seremos nós, que não temos nenhuma relação com ele (PASCAL, 1973, pensamento Br.233/ Laf.418, p. 95, grifos nossos).

Aqui, a razão não pode estabelecer uma relação causal entre Deus e o homem, como afirma Descartes nas Meditações, a partir da ideia de infinito, que estando presente na mente do homem, ser finito, torna-se o principal indicativo de que somente Deus, infinitamente perfeito, pode ser a causa dessa ideia, o infinito devendo ser considerado como a "marca" da perfeição do criador na criatura. Para Pascal, de modo contrário, a distância infinita entre Deus e o homem, já que Deus é "infinitamente incompreensível", impossibilita qualquer possibilidade de relação. Nesse 
caso, não podemos nem fazer qualquer afirmação a respeito da natureza de Deus, assim como não é possível provar a sua existência por intermédio do discurso lógico e racional. Não tendo uma medida comum com Deus, que represente o infinito de modo absoluto e não relativamente a um gênero, por exemplo, infinito extenso, matemático ou infinitamente perfeito, não podemos estabelecer nenhuma relação com o ser supremo, quer ao nível físico, quer ao nível epistemológico.

Nesse sentido, podemos concluir dizendo que Pascal faz uma reflexão a respeito da ideia de infinito não como se este pertencesse a um determinado gênero, como, por exemplo, o infinitamente perfeito, considerado por Descartes nas Meditações, ou até mesmo o infinito pertencente ao gênero extenso e ao gênero quantitativo, presentes na geometria e na matemática. Segundo pensamos, assume fundamental importância no pensamento pascaliano considerar Deus como ser que ultrapassa qualquer gênero, ou seja, como sendo um infinito absoluto. Ora, um filósofo capital que concebe Deus como infinito positivo e absoluto, além de qualquer gênero, é Baruch Espinosa. Analisemos no próximo tópico como o filósofo holandês lida com essa questão e comparemo-lo a Pascal.

O INFINITO EM ESPINOSA E PASCAL

Primeiramente é necessário dizer que, a princípio, Espinosa, profundamente influenciado por Descartes, defende a ideia de que é possível considerar a natureza de Deus partindo do infinitamente perfeito. Essa ideia é defendida nos Princípios da Filosofia Cartesiana, obra escrita em 1663, que como o próprio título diz, é inspirada pela leitura que o filósofo holandês fez da obra Princípios da Filosofia de René Descartes, publicada em 
1644. Nessa obra, Espinosa vai afirmar que a existência de Deus pode ser conhecida através da consideração de sua natureza, em outras palavras, o filósofo holandês vai partir do conceito de Deus para demonstrar a sua existência. Aqui, percebemos o quanto ele é devedor do legado cartesiano. Com efeito, o conceito de Deus só envolve o conceito de existência, pois deus é um ser infinitamente perfeito. Segundo a demonstração da proposição v:

É o mesmo dizer que algo está contido na natureza ou conceito de uma coisa e dizer que algo é verdadeiro dessa coisa (pela def. 9). Ora, a existência necessária está contida no conceito de Deus (pelo ax.6). Logo, é verdadeiro dizer de Deus que a existência necessária está nele, ou seja, que ele existe (ESPINOSA, 2015, p. 87).

É, portanto, pelo conceito de Deus como ser infinitamente perfeito que chegamos à noção de sua existência necessária. É o que Espinosa vai afirmar a partir do lema 1: “Quanto mais perfeita é uma coisa por sua natureza, tanto maior e mais necessária existência ela envolve; e inversamente, quanto mais existência necessária a coisa envolve por sua natureza, tanto mais perfeita ela é.” (ESPINOSA, 2015, p. 97). Com efeito, para Espinosa, o ser necessário e não contingente, capaz de existir por si mesmo, é perfeito na medida em que não depende de uma causa externa a ele para que venha a existir.

Por outro lado, o próprio conceito de Deus como ser infinitamente perfeito nos leva a concluir que ele é um ser necessário, capaz de existir por si mesmo. A esse respeito, Espinosa fornece um exemplo interessante envolvendo certa quantificação da ideia de perfeição. Uma coisa que tem dez graus de perfeição é mais perfeita que algo que envolve cinco graus de perfeição. Ora, se esse grau de perfeição for diminuído até zero, então, conclui o filósofo, estaremos diante do nada, pois algo que não tem 
nenhuma perfeição não conterá nenhuma existência. De outro modo, se aumentarmos essa perfeição até o infinito, essa perfeição envolverá a existência necessária, pois algo infinitamente perfeito deve ser capaz de existir por si mesmo.

Suponha-se então que A seja uma coisa que tem dez graus de perfeição. Digo que seu conceito envolve mais existência do que se supusesse que contém apenas cinco graus de perfeição; pois, como do nada não podemos afirmar nenhuma existência, quanto mais, pelo pensamento, subtraímos da perfeição de A e por conseguinte o concebemos mais e mais participar do nada, tanto mais também lhe negamos de possibilidade de existência. [...] Por outro lado, se aumentarmos ao infinito seu grau, conceberemos que envolve a suma existência, e por conseguinte, sumamente necessária" (ESPINOSA, 2015, p. 97).

Desse modo, fazendo alusão à ideia de perfeição, Espinosa termina por provar a existência de Deus. No entanto, tal posição será ultrapassada na Ética, onde Deus é definido não como um ser infinitamente perfeito, mas como um ser absolutamente infinito, consistindo numa infinidade de atributos: "Por Deus compreendo um ente absolutamente infinito, isto é, uma substância que consiste de infinitos atributos, cada um dos quais exprime uma essência eterna e infinita" (ESPINOSA, 2013, EI, def. 6, p. 13).

Nesse caso, diferentemente daquilo que foi afirmado nos Princípios da Filosofia Cartesiana, Deus é considerado por Espinosa como um ente absolutamente infinito, constituído por infinitos atributos; os atributos, por sua vez, exprimem a essência eterna e infinita de Deus. O homem somente pode ter uma compreensão da essência de Deus, por intermédio dos atributos divinos, pois estes exprimem a natureza eterna e infinita de Deus. A compreensão de Deus como um ser absolutamente infinito se 
afasta da compreensão cartesiana de um Deus infinitamente perfeito, pois infinitamente perfeito, segundo Espinosa, é apenas um gênero de infinitude, não o sendo de modo absoluto. Por isso, na explicação que segue essa definição ele nos diz:

Digo absolutamente infinito e não infinito em seu gênero, pois podemos negar infinitos atributos àquilo que é infinito apenas em seu gênero, mas pertence à essência do que é absolutamente infinito tudo aquilo que exprime uma essência e não envolve qualquer negação (ESPINOSA, 2013, p. 13).

Aquilo que é infinito apenas em seu gênero exprime apenas uma infinitude limitada pelo próprio gênero a qual pertence. Desse modo, o infinito extenso não equivale ao infinito em pensamento, assim como se diferencia do infinitamente perfeito. O próprio pensamento que é considerado por Espinosa como sendo um atributo de Deus se caracteriza por exprimir o infinito apenas dentro de sua própria ordem, não podendo ser equivalente ao infinito extenso, por exemplo. Em contrapartida, não podemos negar nenhum atributo ao absolutamente infinito; sua existência é puramente afirmativa, não envolvendo nenhuma negação.

Nesse sentido, critica a concepção cartesiana de um Deus infinitamente perfeito, já que, nesse caso, infinitamente perfeito seria apenas um gênero de infinitude. Assim, a prova ontológica da existência de Deus na Ética não vai recair sobre o infinitamente perfeito, mas sobre o absolutamente infinito. Segundo Deleuze, na obra Espinosa e o Problema da Expressão:

A prova ontológica, em Espinosa não mais incidirá sobre um ser indeterminado, que seria infinitamente perfeito, mas sobre o absolutamente infinito, determinado como aquilo que consiste numa infinidade de atributos. ( $\mathrm{O}$ infinitamente perfeito será somente o 
modo de cada um desses atributos, a modalidade da essência exprimida por cada atributo) (DELEUZE, 2017, p. 78).

O absolutamente infinito determina de modo mais preciso a natureza de Deus, a qual envolve infinitos atributos ou predicados. Sendo um ser infinito, não pode ser caracterizado por um único atributo, como o de perfeição, por exemplo. Para Deleuze, o infinitamente perfeito é tão somente um "próprio", um predicado de Deus. Sendo um "próprio", não determina Deus de modo tão preciso como a própria noção substancial tomada em sentido absoluto. Segundo Espinosa, na nota 61 do Breve Tratado de Deus, do Homem e do seu Bem Estar, os atributos ou próprios "não são senão adjetivos que não podem ser entendidos sem seus substantivos. Isto é, Deus não seria Deus sem eles, mas não é Deus por eles; pois eles não dão a conhecer algo substancial, pelo qual, somente Deus existe" (ESPINOSA, 2017, nota 61, p. 70). A substancialidade de Deus implica que este ser deve ser tomado como infinito e constituído por infinitos atributos. Tomar um único atributo como representando a natureza de Deus não implica numa demonstração de sua substancialidade.

Os próprios são apenas os adjetivos, os predicados que, longe de definirem a natureza de Deus de modo absoluto, apenas a representam. Nesse sentido, são propriedades de Deus. A propriedade da perfeição, por exemplo, não basta para demonstrar que esse ser não envolve contradição. Para isso, é necessária uma ideia clara e distinta, mais precisamente uma ideia adequada, responsável por fornecer uma definição real, que aponte a própria natureza da coisa e não apenas uma propriedade sua:

Segundo Espinosa, o infinitamente perfeito é tão somente um próprio. Essa propriedade nada nos ensina sobre a natureza do ser ao qual ela pertence; ela não basta para demonstrar que esse ser não envolve contradição. [...] Enquanto não dermos uma definição 
real, que incida sobre a essência de uma coisa e não sobre propria (próprios), continuaremos no arbitrário daquilo que é simplesmente concebido, sem conexão com a realidade da coisa tal como ela é fora do entendimento (DELEuZe, 2017, p. 78).

Essa ideia adequada, por sua vez, somente poderá ser construída no âmbito do entendimento guiado pela própria racionalidade, e não na imaginação. Com efeito, Espinosa, na Carta 12 de sua correspondência, vai distinguir o infinito da imaginação e o infinito do entendimento. O infinito imaginado é aquele fornecido pela imagem dos elementos sendo sucessivamente somados numa progressão infinita, que nunca se interrompe, enquanto o infinito pensado, vinculado ao entendimento, é o infinito indivisível, sendo considerado a afirmação absoluta de si mesmo.

Desta maneira, o infinito imaginado é aquele que uma perspectiva finita constitui a partir de uma adição sucessiva de elementos ou partes, perspectiva que só pode dar conta do caráter infinito da totalidade realizando uma passagem ao limite ou um salto para o além que não pode ser efetivamente concebido pelo entendimento. O infinito pensado ou 'a infinitude filosófica' é, pelo contrário, a presença absoluta, sem além, de uma totalidade indivisível, ou o que Espinosa chama - diz Hegel - 'infinito actu, a afirmação absoluta de si mesmo’ (GAINZA, 2011, p. 90).

Nesse sentido, podemos concluir que, nesse caso, mesmo que o homem não forme uma imagem concreta do infinito como totalidade indivisível, ele pode ser objeto do pensamento, como "infinito pensado", sendo, portanto, passível de compreensão pelo próprio homem. O homem é capaz de ter uma ideia clara e distinta da natureza de Deus, pois concebe pelo pensamento a noção de um Deus infinito constituído de infinitos atributos.

Ora, nada mais distante do pensamento de Pascal, o qual afirma 
que a infinitude indivisível de Deus não pode ser objeto de compreensão do próprio homem. Pascal interpreta literalmente o fato de Deus ser absoluto. Em outras palavras, Deus não tendo partes ou limites e escapando completamente a nossa capacidade de mensuração, deve ser considerado um ser "absoluto", não podendo estabelecer nenhuma "relação" com o homem, o qual deve ser considerado um ser finito, composto de partes e existindo no âmbito de certos limites. Para ele: "O finito se aniquila diante do infinito e torna-se um puro nada. Assim, nosso espírito em face de Deus; assim, nossa justiça em face da justiça divina" (PASCAL, 1973, pensamento Br.233/Laf.418, p. 94).

Em Pascal deve-se falar em "aniquilação" diante de Deus, ser absolutamente infinito, pois, quando se trata deste a incomensurabilidade, ela é tamanha que o homem é reduzido a um "puro nada". Nesse sentido, é impossível fazer qualquer afirmação a respeito do ser supremo. $\mathrm{O}$ absolutamente infinito deve ser assumido como um indicativo do distanciamento absoluto do homem em relação a Deus, implicando a impossibilidade de tecer qualquer forma de discurso lógico sobre o ser divino. Em outras palavras, a questão acerca da existência de Deus não poderá ser resolvida através da razão humana e do discurso lógico-dedutivo.

Por outro lado, o pensamento pascaliano se aproxima do pensamento espinosano na medida em que ambos os filósofos concebem Deus não como algo vinculado a algum gênero de infinitude, seja a extensão ou a perfeição, à maneira de Descartes, mas como o absolutamente infinito. Logo, tanto para Pascal, quanto para Espinosa, Deus é um ser absolutamente infinito, uma totalidade indivisível, que não pode ter sua natureza definida apenas pela ideia de um gênero de infinitude, como por exemplo, o infinito geométrico e o matemático ou até mesmo o infinito vinculado à ideia de perfeição. 
No fragmento Br.233/Laf.418, Pascal vai apresentar uma argumentação bem interessante a esse respeito, respondendo a um interlocutor imaginário que acredita ser impossível que Deus seja um ser infinito, não composto de partes. O pensador francês apresenta como exemplo de um infinito indivisível algo que, embora não possamos provar a existência, pode ser concebido, a saber, um ponto movendo-se por toda parte em velocidade infinita: "Acreditais impossível que Deus seja infinito, sem partes? - Sim. - Quero então mostrar-vos uma coisa infinita e indivisível. É um ponto movendo-se por toda parte em velocidade infinita, pois está em todos os lugares e por inteiro em cada lugar" (PASCAL, 1973, Pensamento Br.231/Laf.420, p. 93). Nesse caso, o suposto interlocutor do fragmento é levado a concluir que, embora existam coisas que ultrapassem o poder de compreensão do homem, tais coisas não deixam de existir pela limitação de nosso intelecto. É perfeitamente possível, portanto, que Deus seja um ser indivisível, para além do gênero de infinitude vinculada à extensão.

Nesse caso, Deus não estaria vinculado a um gênero de infinitude, como por exemplo o infinitamente extenso ou o infinitamente perfeito, mas seria um ente indivisível e absolutamente infinito. Para Espinosa existem dois tipos de infinito: o infinito em seu gênero, que deve ser considerado uma espécie de infinito negativo, na medida em que "só é qualificado de infinito a partir da abstração dos infinitos outros gêneros que permanecem fora dele (separados e alheios) e cujos atributos são negados desse infinito", e o infinito positivo que

[...] seria aquele que Espinosa denomina "absolutamente infinito", ao qual "pertence tudo aquilo que exprime sua essência, e não implica negação alguma", isto é: o próprio ser em si e para si da substância, ou nas palavras de Hegel: "a infinitude absoluta, o positivo, o que aperfeiçoa dentro de si, em presente, uma pluralidade absoluta sem para além (GAINZA, 2011, p. 90). 
Para Espinosa, todos os atributos são infinitos apenas em seu gênero. Ora, a extensão e o pensamento são dois atributos da substância divina, e, portanto, exprimem o infinito dentro de seu âmbito específico. Assim, a extensão é infinita em seu gênero, enquanto o pensamento também é infinito em seu gênero próprio. Cada atributo, mesmo infinito, pertence apenas a seu gênero próprio, não podendo pertencer à natureza de outro atributo. Por isso, para Espinosa, o infinito em seu gênero é aquilo de que é possível negar infinitos atributos.

Por outro lado, para Pascal, a infinitude absoluta de Deus também é considerada algo de outra ordem, pois ultrapassa o próprio gênero relacionado à infinitude extensa e espacial. Isso fica claro pelo pensamento Br.233/Laf.418, já citado anteriormente. Embora possamos pressupor a existência de um infinito extenso, mesmo que não possamos compreender a sua natureza, quando se trata de Deus, ou seja, do infinito absoluto, é impossível pressupor até mesmo sua existência. Com efeito, Deus, o infinito absoluto, além de carecer de limites, pois não se pode negar nada a ele, foge ao alcance de compreensão da própria racionalidade, pois não tem extensão como nós, ou seja, não pode ser medido e compreendido pela razão a partir de coordenadas geométricas ou lógicas. Há uma ausência de critérios quando se trata de demonstrar a existência de um ser absolutamente infinito, pois ele pertence a uma outra ordem de infinitude.

Nesse caso, há um salto qualitativo, e não apenas de ordem quantitativa, quando se trata de passar do infinito de extensão para a infinitude divina. A conclusão de Pascal é que Deus é infinitamente incompreensível para o homem, não havendo nenhuma relação ou medida comum entre o homem e Deus. Ora, para Espinosa, de maneira diferente, o infinito extenso, embora seja apenas um gênero de infinitude, é um atributo de Deus, mais precisamente, um dos infinitos atributos que constituem a essência 
infinita de Deus. Logo, o que torna compreensível a infinitude de Deus em Espinosa é justamente o fato de que o homem é capaz de compreender a natureza do atributo extensão, assim como compreende também a natureza do pensamento como sendo um dos atributos da substância divina. Logo, como os atributos (extensão e pensamento) exprimem a natureza divina, o homem pode compreender a essência de Deus através dos atributos da substância infinita.

Em Pascal, há total diferença de ordem entre o infinito extenso e o absolutamente infinito. Nesse caso, não se pode estabelecer nenhuma relação entre uma ordem de infinitude e outra, pois ambas são de natureza qualitativamente diferente. $\mathrm{O}$ mesmo não se pode afirmar, por exemplo, quando se trata das duas ordens de infinitude encontradas na natureza, o infinito de pequenez e o infinito de grandeza, as quais estão fundamentadas no infinito de divisibilidade e no infinito de multiplicidade. Entre essas duas ordens há homogeneidade e não heterogeneidade. A noção de homogeneidade entre duas ordens de infinitude, por sua vez, Pascal extraiu do axioma de Eudoxo.

Segundo Ivonil Parraz, a noção de duplo infinito decorre da interpretação pascaliana do axioma de Eudoxo. 'Duas grandezas quaisquer, quando uma é multiplicada um número suficiente de vezes, poderá tornarse maior que a outra'. A proposição I do livro x de Euclides se fundamenta sobre esse axioma (PARRAZ, 2012, p. 271).

Pascal, ao interpretar o axioma de Eudoxo, extrai daí a possibilidade da multiplicação infinita de tudo que existe na natureza concebendo a impossibilidade da compreensão da totalidade do universo e, do mesmo modo, extrai também a possibilidade da divisibilidade paralela em relação 
às menores coisas, o que aponta para uma relação entre duas grandezas, vinculadas, respectivamente, ao macrocosmo e ao microcosmo. O próprio Euclides, segundo Pascal, se fundamenta sobre esse axioma de Eudoxo: “as grandezas, diz ele [Euclides], são ditas serem do mesmo gênero, quando uma sendo várias vezes multiplicada pode chegar a ultrapassar a outra" (PASCAL, 1963, p. 354a).

Nesse caso, é lícito concluir que, sendo as duas grandezas, o infinito de grandeza e o infinito de pequenez, do mesmo gênero, pois uma pode ultrapassar a outra, elas são homogêneas entre si. A característica de homogeneidade é indicativa do fato de que uma grandeza pode ultrapassar a outra indefinidamente, relacionando-se por meio desse ultrapassamento.

O que equivale a afirmar que se duas grandezas são do mesmo gênero elas são homogêneas. Sendo homogêneas, elas não podem cessar de continuar em qualquer direção que seja. O espaço, por exemplo, não só pode ser multiplicado como também dividido infinitamente. [...] De tudo aquilo que pode ser aumentado segue absolutamente que pode ser diminuído, pois sendo homogêneas as grandezas, e uma vez que se pode aumentá-las infinitamente, conforme o axioma de Eudoxo, este aumento infinito encerra a divisão infinita. $\mathrm{O}$ infinitamente grande e o infinitamente pequeno, embora diferentes, são relativos um ao outro, exatamente por sua homogeneidade (PARRAZ, 2012, p. 271).

Assim, não há uma diferença qualitativa entre o infinitamente grande e o infinitamente pequeno, mas apenas diferença quantitativa, pois sendo homogêneos são relativos um ao outro. Segundo Pascal: “[...] esses dois infinitos, ainda que infinitamente diferentes, são, contudo, relativos um ao outro, de tal modo que o conhecimento de um leva necessariamente ao conhecimento do outro" (PASCAL, 1963, p. 354b). 
No fundo, a dupla infinitude é expressão do infinito potencial, que implica na ideia de que tudo que pode ser potencialmente multiplicado também, em caminho inverso, pode ser potencialmente dividido. "O duplo infinito, que Pascal concebe como propriedade comum de todas as coisas, é somente o infinito potencial, isto é, a possibilidade de ir sempre além em qualquer direção" (PARrAZ, 2012, p. 272). A homogeneidade, portanto, presente nas duas ordens de infinitude nos leva a relacioná-las entre si. No entanto, entre o infinito quantitativo e espacial e o infinito absoluto (Deus) embora haja a possibilidade de estabelecer uma relação comparativa, até certa medida, por intermédio da analogia com um ponto indivisível, movendo-se em velocidade infinita, há total diferença de ordem. Se o infinito absoluto ultrapassa infinitamente o infinito, cujo gênero é extenso, é justamente porque é de uma ordem completamente diferente, sendo, portanto, completamente heterogêneo a este. Nesse caso, não há medida comparativa de mesmo gênero que permita fazer a analogia e, consequentemente, a passagem de um infinito a outro. O "ultrapassamento" não se refere a uma distância que pode ser compreendida e medida pelo intelecto, mas revela uma posição além daquilo que pode ser compreendido e medido pela razão.

Tal como ocorre em Espinosa, portanto, Pascal também afirma a ideia de um infinito absoluto, que ultrapassa qualquer gênero de infinitude. No entanto, há uma diferença entre os dois autores, que reside na categoria de "relação". Enquanto para Espinosa os atributos infinitos em seu gênero próprio "relacionam-se" com o absolutamente infinito por serem constituintes da substância divina, para Pascal não há qualquer espécie de "relação" entre a ordem de realidade à qual pertence o absolutamente infinito, e a ordem de realidade à qual pertence o infinitamente pequeno e o infinitamente grande, que correspondem ao infinito de gênero extenso e espacial. Pascal, fiel ao pensamento de Eudoxo, defende a ideia de que 
somente há relação entre ordens de mesma grandeza. Se o infinito dos matemáticos e dos geômetras é meramente quantitativo e espacial, como passar do infinito quantitativo e potencial, caracterizado pela possibilidade de divisibilidade e multiplicidade infinitas, para a pura presença do infinito absoluto (Deus), puramente qualitativo e não quantitativo? Logo, não há relação possível, mas há, sim, distância infinita.

Assim, Pascal e Espinosa se aproximam quando não consideram a infinitude divina como num determinado gênero, seja o gênero extenso ou aquele vinculado à ideia de perfeição. Por ser infinita, no sentido absoluto, a natureza de Deus é muito maior do que os próprios atributos, diria Espinosa, ou do que o infinito extenso encontrado na natureza, diria Pascal. No entanto, o pensamento dos dois autores se afasta quando Espinosa afirma a possibilidade de compreensão do absolutamente infinito, por intermédio de dois de seus atributos, a extensão e o pensamento, ao passo que Pascal afirma a impossibilidade de compreensão do absolutamente infinito em decorrência de ele não estabelecer nenhuma relação nem com a extensão, nem com o pensamento. Em outras palavras, o Deus pascaliano transcende a natureza extensa, e ultrapassa as capacidades lógico-racionais.

Nesse sentido, ao contrário do filósofo holandês, que concebe a possibilidade de conhecê-lo através do conhecimento de dois de seus atributos, a extensão e o pensamento, para Pascal, Deus, por ser o próprio absoluto, é um ser "infinitamente incompreensível". Em outras palavras, nesse caso, a natureza absolutamente infinita de Deus é o índice que aponta para a ignorância do homem, no que tange à possibilidade de provar de modo racional que o ser supremo é e existe. Não há prova ontológica da existência de Deus em Pascal, sendo impossível estabelecer qualquer forma de analogia ou mesmo qualquer relação entre Deus e o homem. Assim, afirma Ivonil Parraz: 
Entre o homem (finito) e Deus (infinito) não é possível estabelecer analogia alguma, e por via de consequência, a existência ou não de Deus não se impõe à razão. Não tendo nenhuma relação conosco Deus está fora da captura da razão. O Deus pascaliano não é identificado às verdades geométricas. $\mathrm{O}$ conhecimento destas não redunda no conhecimento de Deus. Com efeito, nenhum discurso é possível sobre ele. Diante da divindade só cabe à razão o silêncio (PARRAZ, 2012, p. 278).

Daí porque o fragmento Br.233/Laf.418, que discute essas questões acerca do infinito, desemboca no argumento que discute a necessidade de se apostar em Deus. É que não havendo a possibilidade de construir uma prova racional a favor da existência de Deus, a única alternativa é inclinar a vontade na direção de uma aposta no âmbito da fé. Nesse quesito, o próprio Pascal é bem claro: “Deus existe ou não existe’. Para que lado nos inclinaremos? A razão não o pode determinar: há um caos infinito que nos separa. Na extremidade dessa distância infinita, joga-se cara ou coroa” (PASCAL, 1973, pensamento Br.233/Laf.418, p. 95).

Aqui nos deparamos com o "infinitamente incompreensível", ou seja, há uma distância infinita que nos separa de Deus. Essa distância infinita é ressaltada também no fragmento Br.793/Laf.308 sobre as três ordens de realidade. Para Pascal há três ordens de realidade, os corpos, os espíritos e a caridade, podendo o homem pertencer a cada uma dessas ordens: há aqueles que se ocupam com as grandezas carnais, vivendo a dimensão relacionada ao corpo e aos prazeres sensíveis e materiais, aqueles que se ocupam com as grandezas espirituais, e estes são os filósofos e os homens de ciência, e há também aqueles que se ocupam com aquilo que representa a caridade, como Deus e a religião, sendo estes objetos de ordem sobrenatural. Cada uma dessas ordens é irredutível à anterior, havendo uma distância infinita entre elas, em função de sua heterogeneidade e de sua incomensurabilidade. Desse modo Pascal afirma: 
A distância infinita dos corpos aos espíritos figura a distância infinitamente mais infinita dos espíritos à caridade, pois ela é sobrenatural [...] De todos os corpos juntos não poderíamos extrair um pequeno pensamento; isso é impossível e de outra ordem. De todos os corpos e espíritos não poderíamos tirar um movimento de verdadeira caridade; isso é impossível e de outra ordem, sobrenatural (PASCAL, 1973, pensamento Br.793/Laf.308, p. 244).

Desse modo, assim como no fragmento Br.233/Laf.418, no fragmento Br.793/Laf.308 Pascal aponta para uma distância infinita entre o pensamento, que produz conhecimento demonstrativo e lógicodedutivo, e a ordem da caridade, a qual está relacionada ao âmbito da fé e, consequentemente, a Deus. Em outras palavras, nesse caso, a heterogeneidade entre as ordens, por cada ordem ser qualitativamente diferente da outra, estabelece uma distância infinita entre elas.

De certa maneira, podemos dizer que, assim como há uma distância infinita entre a ordem do espírito e a ordem da caridade, no fragmento Br.233/Laf.418 há uma distância infinita entre o infinito presente na matemática e na geometria, que permite que possamos chegar à conclusão de uma dupla infinitude no âmbito do universo, e o infinito absoluto representado por Deus. Nos dois casos, existe um abismo infinito e, portanto, é possível concluir que, quando Pascal faz afirmações a respeito do infinitamente absoluto e da ordem da caridade, ele os define como infinitamente incompreensíveis para o âmbito do espírito, ou seja, da razão. Nesse caso, a única alternativa é apostar na existência de Deus, o que fica visível no fragmento Br.233/Laf.418, ou assumir a ordem da caridade como fundamento da existência, como aponta o fragmento Br.793/Laf.308. 
CONCLUSÃO

Embora Pascal não seja enquadrado, juntamente com outros filósofos, no rol daqueles pensadores que idealizaram e construíram um grande sistema metafísico a partir de um Deus infinito que daria sentido à realidade como um todo, não podemos deixar de perceber sua importância dentro do debate sobre o infinito no século XVII. Diferentemente dos outros autores desse período, no entanto, ao construir um discurso sobre a natureza infinita de Deus, o filósofo jansenista interpreta literalmente o sentido da expressão "infinito absoluto". Com efeito, Pascal, ao compreender Deus como o absolutamente infinito, conclui que esse ser, por ser absoluto, ultrapassa o gênero de infinitude vinculado à geometria e à racionalidade, não estabelecendo nenhuma relação com aquilo que é finito, ou seja, com o homem.

Nesse sentido, Pascal ultrapassa a ideia de um Deus cartesiano considerado apenas como infinitamente perfeito, visto que a perfeição seria apenas um gênero de infinitude, e aproxima-se do pensamento espinosano, quando define Deus como absolutamente infinito, acima de qualquer gênero. Para Espinosa, Deus pode ser conhecido pela racionalidade como infinito positivo, o ser em si da substância, em virtude de que conhecemos racionalmente os dois atributos pelos quais a substância infinita se expressa, a extensão e o pensamento. No entanto, para o autor jansenista, de modo oposto a Espinosa, Deus, sendo considerado o absolutamente infinito, é considerado literalmente como "absoluto" e, nesse sentido, não estabelece relação alguma com as coisas finitas e nem com o pensamento. $\mathrm{O}$ infinito absoluto não permite qualquer tipo de critério de compreensão, no âmbito da racionalidade, o que faz com que Pascal desloque essa questão para além da esfera da razão, assumindo-a dentro da possibilidade de uma aposta em Deus ou da conversão para a ordem da caridade. 
Desse modo, o conceito de infinito em Pascal deve ser compreendido não como aquilo que permite a construção de uma metafísica calcada na ideia de um Deus absoluto, mas como um indicativo da limitação do conhecimento racional. Muito mais do que tecer um discurso sobre Deus como sendo um ser infinitamente positivo de potência ilimitada, Pascal o define como "infinitamente incompreensível".

Assim, é importante dizer que, embora Pascal não construa um sistema metafísico a partir da categoria da infinitude, ele deve ser colocado como um autor que ombreia com os outros autores do século XVII quando opera uma discussão em torno da questão do infinito em âmbito divino. Mesmo que o filósofo jansenista conclua que a razão é impotente quando se trata de conhecer Deus, a discussão em torno da ideia de infinitude relacionada ao ser divino é frutífera no que tange ao diálogo que Pascal pode estabelecer com os outros filósofos do século XVII. Com efeito, tal discussão, ao fazer uma reflexão sobre o conceito de infinito desenvolvido na matemática e na geometria e compará-lo com outra ordem de infinitude, o infinito absoluto, desemboca numa perspectiva frutífera e rica quando se trata de pensar os grandes sistemas metafísicos do XVII.

Embora não haja prova da existência de Deus em Pascal, ao refletir sobre o infinito, Pascal nos leva a um outro lado dessa questão: é justamente a concepção de um Deus infinito que afasta o homem da possibilidade de compreensão da natureza desse ser, o que resulta na impossibilidade do pensamento metafísico, mas sem desconsiderar a infinitude como um elemento central que expressa a natureza desse ser. Nesse sentido, mesmo que a filosofia pascaliana não desemboque num "fascínio" por uma prova ontológica da existência de Deus, como ocorre com outros autores do século XVII, o raciocínio pascaliano se avém com o infinito retirando 
conclusões que estabelecem um novo critério para pensar essa questão. Por isso, mesmo sem prova ontológica, concordamos com Homero Santiago que, na introdução à edição em português das Meditações Metafísicas de Descartes, afirma:

O fascínio de uma prova da existência de Deus em qualquer dos grandes sistemas do XVII é sempre aquele despertado pela chegada do instante supremo em que o raciocínio invariavelmente tem de avir-se com o infinito, seja lá como este infinito for concebido, segundo o talante de cada pensador. Em outras palavras, trata-se também de uma prova da racionalidade, uma investigação acerca das próprias possibilidades do pensamento e da verdade; a prova dos nove de qualquer racionalismo do XVII [...] (SAntiago apud DeSCARTES, 2016, p. 23).

Assim, mesmo que Pascal não tenha criado nenhum sistema metafísico, não é errôneo pensar que, talvez, Pascal, quando reflete sobre o infinito, esteja investigando também, tal como outros autores do período, as "possibilidades do pensamento e da verdade" no panorama do século XVII. A diferença é que sua investigação, longe de desembocar no racionalismo, vai propor uma nova medida para o pensamento filosófico, de agora em diante não mais calcado numa metafísica que reduz Deus à medida racional do homem, mas fundamentado na noção dos limites do conhecimento, ou seja, a partir daquilo que o homem pode ou não conhecer no âmbito de seus critérios racionais. 


\section{THE QUESTION OF INFINITY IN PASCAL AND SPINOZA}

ABSTRACT: The main objective of this article is to demonstrate that the thought of the French philosopher Blaise Pascal was never unaware of the main metaphysical discussions of the 17th century. The discussion that will be explored here is related to the question of infinity, explored with emphasis by the authors of that period. With this objective in mind, we will try to build an argument on the question of infinity in the metaphysics of two 17th century philosophers: Blaise Pascal and Baruch Espinosa. We will try to show that Pascal's philosophical reflection, on the one hand, resembles that of Spinoza when he assumes that God must be conceived as absolutely infinite, beyond any specific kind of infinity, whether mathematical or spatial, but he distances himself from the Dutch philosopher when he assumes that it is impossible for man to understand the infinite in absolute terms through rationality.

KEYWORDs: Infinity, Geometry, Mathematics, God, Metaphysics, Boundary.

\section{REFERÊNCIAS BIBLIOGRÁFICAS}

BRunschVicG, L. (1945). Las Etapas de La Filosofia Matematica. Traducción: Cora Ratto de Sadoski, Buenos Aires: Editorial Lautaro.

Deleuze, G. (2017). Espinosa e o Problema da Expressão. Tradução: GT Deleuze. São Paulo: Editora 34.

Descartes, R. (2016). Meditações Metafísicas. Tradução: Maria Ermantina de Almeida Prado Galvão. Introdução e notas Homero Santiago. São Paulo: Martins Fontes.

Gainza, M. (2011). Espinosa: Uma Filosofia Materialista do Infinito Positivo. São Paulo: Edusp. 
espinosa, B. (2017). Breve Tratado: de Deus do Homem e do seu Bem-Estar. Tradução: Emanuel Angelo da Rocha Fragoso e Luís César Guimarães Oliva. Belo Horizonte: Autêntica Editora.

. (2013). Ética. Tradução: Tomaz Tadeu. Belo Horizonte: Autêntica Editora. - (2015). Princípios da Filosofia Cartesiana e Pensamentos Metafísicos. Tradução: Homero Santiago e Luís Cesar Guimarães Oliva. Belo Horizonte: Autêntica Editora.

Lebrun, G. (1983). Blaise Pascal: Voltas, Desvios e Reviravoltas. Tradução: Luiz Roberto Salinas Fortes. São Paulo: Brasiliense.

parraz, I. (2012). As Concep̧ões Pascalianas de Infinito e a Incompreensibilidade de Deus e do Mundo. Revista Dissertatio de Filosofia, [S.1.], v. 35, p. 267-295, jul. 2012. ISSN 1983-8891. Disponível em: <HTTPS://PERIODICOS. UFPEL.EDU.BR/OJS2/INDEX.PHP/DISSERTATIO/ARTICLE/ VIEW/8691>.

Pascal, B. (1963). Euures Complètes. Paris : Éditions du Seuil. . (1973). Pensamentos. Tradução: Sérgio Milliet. São Paulo:

Abril Cultural.

SERres, M. (1968). Le Système de Leibniz et ses Modèles Mathématiques. Paris : Presses Universitaires de France. 